\title{
O RELATO DE UMA TEMPESTADE ANUNCIADA: HISTÓRIAS DE CURA DE UM LAMA TIBETANO
}

\author{
Ana Cristina Lopes Nina
}

Resumo: $\mathrm{O}$ ponto de partida deste artigo é um episódio ocorrido em plena floresta amazônica, durante uma viagem realizada por Lama Gangchen, um conhecido lama tibetano curador, e seus discípulos. Uma tempestade anunciada, um rio revolto, uma longa e apreensiva caminhada, e uma cura milagrosa são alguns dos elementos que compõemesta narrativa etnográfica, em muitossentidos, fantástica. Entre outras coisas, será analisado aqui como um evento relativamente privado, como a cura realizadapor LamaGangchen, pode ganhar dimensõesmundiais(e mesmouniversais) através da prática de um ritual. Como veremos, se Lama Gangchen no início de sua estada no Ocidente enfatizou seu poder de curar doenças, etc., nos últimos anos, ele dá uma nova conotação a esse papel. Sua prática de "autocura do meio ambiente" que relaciona o corpo de cada um de nós com o meio ambiente que nos rodeia representa uma expressáo quase alegórica da tensão entre o global e o local e nos dá pistas de como a conjugação entre os vários níveis de sua atuação se desdobra para gradualmente construir para ele a imagem de um curador do mundo.

Abstract:The startingpointof thisarticleis an episodethat tookplacein theAmazonian rain forest, during a trip with Lama Gangchen - a Tibetan Buddhist lama known for his healing powers - and his disciples. A foretold storm, a troubled river, a long and frightening walk,and a miraculoushealing are some of the elements that compose this ethnographical narrative, which could, in many senses, be seen as a fantastical one. Among other things, what would be analyzed here is how a relatively private event i.e. the healing realized by Lama Gangchen - can acquire worldwide dimensions (and evenuniversalones)through thepractice of a ritual.If LamaGangdhen, in thebeginning of its encounter with the West emphasized his capacity to heal actual diseases, in more recent years, he invested this role with a new meaning. His spiritual practice "Selfhealing of the environment", which correlates our bodies with the environment represents an almost allegoric expression of the tension between the global and the local and give us hints on the way that the various levels of his activities are combined in order to gradually build for himself an image of a World Healer.

Doutora em Antropologia Social pela Universidade de São Paulo (USP) (anacritinalopes@hotmail.com). 


\section{A CURA}

Floresta Amazônica, janeiro de 2001. Desde cedo já se sabia que uma tempestade estava a caminho. Passamos o dia ouvindo pelo rádio a previsão do tempo e vendo ao longe o relampejar do céu. Na comunidade ribeirinha de Suruacá uma festa havia sido programada para aquela noite. A população local chegara a preparar uma apresentação de palhaços para recepcionar Lama Gangchen, mas diante das condições meteorológicas não era possível prever se conseguiríamos atracar ou não. Havia seis dias viajávamos pelo rio Tapajós em um barco que além de nosso meio de transporte era também nossa "casa" - as redes coloridas on de dormíamos se espalhavam pelo convés.

Quando à tarde atracamos no chamado "Abrigo dos Golfinhos", próximo à Suruacá, o médico Eugênio Scan navino, do "Saúde e Alegria", a ONG que organizou a viagem juntamente com a AACHAA (a Associação de Artes Curativas do Himalaia, Andes e Amazônia criada por Lama Gangchen), mandou uma "voadeira" até a comunidade, no intuito de confirmar se o evento aconteceria ou não. Chegou então a informação de que a população nos esperava desde o meio-dia. Decidiu-se, portanto, que um grupo iria até Suruacá. Por uma questão de segurança, Lama Gangchen ficaria no barco, uma vez que era certo que, mais cedo ou mais tarde, a tempestade chegaria. Sem perceber inicialmente que o lama tibetano não estava com o grupo, a comunidade o recepcionou, com músicas e cartazes dando-lhe as boas-vindas. A apresentação (um show com palhaços) demorou cerca de uma hora. Todos nós já estávamosextremamente exaustosdevido ao longo dia que havíamos tido. Terminada a apresentaçáo, fomos comprar artesanato.

Finalmente começamos a nos preparar para ir embora. Porém, quando chegamos à margem do rio, descobrimos que os barqueiros haviam desaparecido. Cerca de dez minutos depois, os dois reapareceram. Algumas pessoas já haviam garantido seu lugar na primeira leva. Depois de fazer a primeira

O presente artigo foi escrito com base nos capítulos 5 e 6 de minha tese de doutorado, Ventos da Impermanência: um Estudo sobre a Re-significação do Budismo Tibetano no Contexto da Diáspora, publicada pela Edusp em maio de 2006. 
viagem, veio o anúncio: o rio estava muito revolto, e o barco onde dormíamos não podia continuar onde estava. $\mathrm{O}$ plano era tentar atracar em frente ao hotel de selva, onde havíamos passado o Ano Novo. Apenas pessoas que estivessem machucadas ou acompanhadas de crianças foram levadas para o barco a partir da praia de Suruacá.

Foi aí que começou nossa pequena aventura. Com apenas algumas lanternas em mãos, caminhamos mais de uma hora pela praia. Enquanto eventualmente iluminavam nosso caminho, os relâmpagos iam anunciando que a tempestade estava cada vez mais próxima. Ao longe víamos o barco que, ao contrário do que esperávamos, parecia estar cada vez mais distante.

Quando chegamos ao local combinado, o barco não estava mais à vista. Sentamos um pouco na areia. Algumas pessoas, tentando entender o que estava acontecendo, começaram a fazer perguntas aos coordenadores da viagem, que, por sua vez, responderam com impaciência e nervosismo. O mote era: "não entrem em pânico, vamos ficar quietos e rezar mantras". As pessoas, obviamente, não se conformaram com a resposta e o tratamento, e continuaram a pedir explicações. Foi aí que Sassá, um homem da região que estava trabalhando para a ONG Saúde e Alegria, explicou que a "voadeira" que poderia nos levar até o barco fora usada para resgatar uma pessoa da comunidade que havia passado mal - a informação que obtivemos, através de Sassá, era que essa pessoa havia sofrido uma parada cardíaca. Ele disse também que o barco não conseguia atracar ali porque o rio estava batendo muito. Todos ficaram mais calmos com essa explicação simples.

Depois de esperar um pouco, alguém deu a sugestão de que dormíssemos no saguão do hotel de selva. Christian, o argentino que se juntou ao grupo de Lama Gangchen depois que a viagem já havia começado, foi até o hotel e pediu aos funcionários para que ficássemos por lá. Com a permissão deles, fomos todos até o hotel. Talvez uns quinze minutos mais tarde, Rui, um amigo de Eugênio que não era discípulo de Lama Gangchen, chegou com a informação de que o barco estava atracado a uns vinte minutos dali. Mais uma vez saímos em comboio.Essa caminhada foi mais dura, pois passamos por trechosonde praticamente não se pisava em areia, apenas em troncos e pedras. Neste momento, algumas pessoas começaram a entrar em pânico. 
Andamos ainda mais do que no primeiro trecho. Quando chegamos num ponto onde estava Rui, sentamos e esperamos pela voadeira. Ninguém realmente estava entendendo nada, pois a voadeira não estava lá. Pouco mais de dez minutos depois, chegou uma discípula de Lama Gangchen, bastante nervosa, gritando para Christian. Ela explicou que a voadeira havia virado e que ela estava tendo desvirá-la com a ajuda dos barqueiros já havia mais de uma hora. Todos os homens foram ajudar a desvirar a voadeira. Em dois minutos ela já estava desvirada, mas agora o motor não pegava.

Enquanto consertavam o motor, algumas pessoas tentaram conversar com um dos coordenadores da viagem, a fim de persuadi-lo a ir até o lugar onde estávamos anteriormente, para embarcar.O rio parecia estar mais tranqüilo naquele ponto. $\mathrm{O}$ coordenador não apenas não quis escutar, mas respondeu com certa grosseria. "Uma coisa de cada vez, agora estamos consertando o barco". Quando o barco já estava funcionando, e as pessoas embarcando, mais uma vez tentaram conversar com ele. E ele deu a mesma resposta. A coisa quase evoluiu para uma briga.

No minuto em que as pessoas estavam embarcando, caiu finalmente a anunciada tempestade. Naquele que certamente foi o momento mais confuso e dramático da nossa pequena aventura, algumas pessoas corriam para embarcar, apesar da inusitad a violência que o rio tinha adquirido - no grupo dos apressados estava inclusive uma discípula de Lama Gangchen que não sabia nadar. $\mathrm{O}$ outro grupo preferiu esperar na margem até que a tempestade passasse. Aos poucos as voadeiras foram levando as pessoas. E, tendo nosso barco acendido seu farol, conseguíamos enxergar finalmente o trajeto. Chovia torrencialmente, mas os raios felizmente não caiam perto dali. Aos poucos tudo foi se acalmando.

Fui na últimaviagem da voadeira. Naquele momento, o rio já estava bem maiscalmo.Quando chegamosao barco, Débora estava lá paranos recepcionar. Eram três da manhã. Descobrimos naquele momento que a pessoa que tinha passado mal estava sendo tratada por Eugênio e Bel - Isabel Villares, a mãe do Lama Michel, que épsicóloga e trabalha com doentes terminais - ali mesmo no nosso barco. Seus familiares rondavam, silenciosos, o camarote onde estava deitado. Perguntei logoa Eugênio como ele estava, e ele disseque provavelmen- 
te ele não iria passar daquela noite. Conversando com Bel, alguns minutos depois, ela também disse que ele morreria em algumas horas. De manhã o vimos sendo carregado para o barco de apoio, enquanto gemia.

Só no dia seguinte saberíamosmais detalhes da história.Eugênio contou que ele foi chamado no meio da apresentação do circo. Manuel, um homem de mais de sessenta anos, tivera um acidente vascular cerebral. Antes mesmo de ele ser transportado até o barco, seu Manuel já estava inconsciente, e já havia tido uma parada cardíaca. Quando estava sendo levado na voadeira, teve mais uma parada cardíaca, bem no momento em que o motor havia pifado. Eugênio teve que massagear seu peito ali mesmo. Teve também convulsóes. Ao todo, ele teve três paradas cardíacas e cinco convulsóes.

Eugênio contou que Lama Gangdhen foi chamado para ver o paciente. $\mathrm{O}$ lama colocou um remédio tibetano na sua boca, e deu umas sopradas. Seu Manud, que estava inconsciente há horas, acordou no mesmoinstante.E acordou falando.Seus familiaresficaramimpressionados. Depois disso, sua paralisia - estava paralisado da cintura para baixo - começou a regredir. Eugênio disse que nuncaviu um paciente evoluir dessamaneira. "Maisum que não morrena minha mão", teria pensado naquele momento. O que aconteceu depois ele só saberia alguns dias mais tarde. Seu Manuel foi levado até Alter do Chão, a maior cidade nas redondezas, em um barco de apoio. Dali ele foi por terra até Santarém. Apenas em São Paulo eu ficaria sabendo, através do próprio Eugênio, que seu Manud tinhase recuperadocompletamente, e deixado o hospital, andando e falando normalmente. Ele disse ainda que os médicos não acreditaram no que viram, especialmente porque ele não ficou com nenhuma seqüela.

\section{O CURADOR}

Talvez uma das mais conhecidas metáforas budistas seja aquela que considera o Buda como o médico supremo, os ensinamentos budistas como a mais elevada formade medicina,e a comunidadeespiritual budista, ou sangha, como a equipe de enfermeiros. $\mathrm{O}$ entendimento da idéiade curano budismo, porém, não se restringe a esta famosa metáfora, abrangendo muitas vezes dimensões mais pragmáticas, como a investigação acerca das causas espirituais e físicas de 
doenças e ainda a cura em si, através do uso de ervas mediainais, ou até mesmo de cirurgias (Birnbaum, 1989, p. 3). A centralidade do conceito de cura, em suas diversas acepçóes, parece ser particularmente verdadeira no caso do budismo tibetano, sistema no qual práticas medicinais importadas da Índia, e em especial da Medicina Ayurvédica, foram amplamente desenvolvidas, chegando o Tibete a ser conhecido na Ásia Central como o "país da medicina” e a "terra das plantas medicinais" (Clifford, 1984, p. 3-4).

Muitos lamas tibetanos são, na verdade, médicos de fato. Este é o caso de Lama Gangchen que, já a partir da idade de treze anos, passou a estudar disciplinas médicas e afins, como anatomia, fisiologia, a composição e a interação entre várias substâncias medicinais, e a administrá-las (Gangchen, 2001, p. 15). Reconhecido dentro de uma linhagem de lamas curadores, Lama Gangchen iria ainda além do papel de médico de formação. Desde cedo, conta sua biografia, realizaria curas ditas milagrosas.

Assim, quando desembarcou pela primeira vez em terras ocidentais, mais especificamente na ilha grega de Lesbos, em 1981, trazendo na bagagem apenas algumas poucas palavras de inglês, sua principal forma de comunicação foi naturalmente o dom da cura. Lama Gangchen fundou seu primeiro centro no Ocidente, o Karuna Choestok, na Ilha de Lesbos, com a ajuda de uma italiana que curara de câncer. Histórias como essa se repetiriam nas diversas etapas da inserção deste lama no Ocidente.

Durante a década de 80, Lama Gangchen viajaria intensamente pelo mundo, visitando países onde havia aberto centros e ao mesmo tempo criando, pelo caminho, novos centros. Muitas vezes, as curas pessoais que realizava lançavam as sementes para a construção de novos espaços públicos, a partir dos quais Lama Gangchen foi criando uma rede internacional de discípulos. No Brasil, onde foi inaugurado um dos primeiros centros de Lama Gangchen, o Centro de Dharma Shi De Choe Tsog, em 1987, a história não foi diferente. Isabel Villares Lenz Cesar, fundadora do centro, conta que o que levou as pessoas a entrarem em contato com o centro em primeiro lugar foi mais uma vez a busca da cura.

Não sei como, um jornalista da Folha descobriu que ele [Lama Gangchen] viriae ficou atrás de mim para conseguir mais informaçōes. $O$ fato é que a notída de 
que Rinpoche viriaacabou saindo na primeira página da Folha. Apareceram mais de quinhentas pessoas na conferência que o Rinpoche deu. E todos os dias mais de cem pessoas apareciam na minha casa, onde ele estava hospedado, todas atrás da cura [...]. Eu pensei: "Jesus Cristo baixou aqui e está fazendo milagres". E eu vi que através do sopro e de algumas cuspidas, ele curou muita gente. Tinha uma menina que chegou com um gânglio muito inchado na virilha; ela não podia nem sentar. E como ela era alérgica a anestesia, ela veio desesperada, pois não podia operar. O Rinpoche tratou dela, e uma semana depois ela voltou com um ramo de flores para agradecer e disse que o gânglio foi desaparecendo a cada dia.

Lama Gangchen se diferenciava de muitos lamas, como por exemplo Lama Yeshe e Lama Zopa, que já atuavam no Ocidente há um certo tempo. Não dava muitos ensinamentos. Na verdade, praticamente não falava, realizava apenas, contam seus discípulos mais antigos, a transmissão do mantra de Buda Shakymuni: Om Muni Muni Shakya Muni Maha Muniye Soha. Lama Gangchen dizia que este era um mantra de cura e aconselhava seus discípulos que sua recitação fosse acompanhada de visualizações nas quais emoçôes negativas, tais como o ciúme, a raiva, a inveja, etc., e negatividades do corpo, palavra e mente fossem imaginados como uma luz negra que eliminamos no momento da expiração. ${ }^{1}$

\footnotetext{
${ }^{1}$ Em seu livro Autocura, que seria publicado pela primeira vez no Brasil, em 1991, Lama Gangchen explica o significado de cada sílaba do mantra:

"Om: a tranqüilidade e a felicidade mental absoluta.

Muni: a determinação de renunciar ao Samsara, o desejo intenso de se livrar de todos os sofrimentos.

Muni: a determinação de manter a motivação de uma mente altruísta, a mente de Bodhicitta que deseja ajudar a todos.

Maha Muni: representa a visão correta da realidade, isto é, a percepção de que todos os fenômenos são de natureza vazia, auseuntes de conceitos e que não possuem uma existência indepentente.

Shakya Munyie: representa o caminho secreto (tântrico), que é o mais veloz.

Milhares de Buddhas já vieram para o nosso mundo, porém Buddha Shakyamuni foi o único que transmitiu os ensinamentos tântricos.

Soha: quer dizer: "Por favor, dê-me estas realizações pelo benefício da au ra" (Gangchen, 2001, p. 61)
} 
Como conta Mônica Benvenuti, sua primeira aluna brasileira, Lama Gangchen chegou ao Ocidente em uma época de transição; alguns lamas importantes, como Lama Yeshe e Gueshe Rabten, haviam falecido há pouco. Na opiniāo de Mônica, Lama Gangchen "era o lama do momento: tanta teoria tinha sido falada, tanto ensinamento daqui e dali, e Rinpoche simplesmente punha em prática, em ação mesmo, o famoso dharma”. O estilo voltado para a prática de Lama Gangchen se traduzia muitas vezes por mudanças muito concretas na vida de seus alunos. A própria Mônica tomaria cruciais decisões em sua vida seguindo os conselhos práticos de Lama Gangchen. No começo dos anos 90, por exemplo, ele sugeriria que ela se mudasse para Milão onde, graças à doação de um prédio feita por um discípulo italiano, Franco Ceccarelli, havia sido montado seu primeiro centro de dharma na Itália, o Kunpen Lama Gangchen. Durante alguns anos, Mônica e outros discípulos viveram junto a Lama Gangchen no próprio centro. Quando Lama Gangchen se mudou para seu novo centro na região do Lago Maggiore, a uma hora e meia de Milão, Mônica seria uma das primeiras a comprar um apartamento na área. Hoje divide sua vida entre Milão, onde mora com seu marido e trabalha na loja de artigos de dharma do Kunpen Lama Gangchen, e o Albagnano Healing Meditation Center, onde passa os finais de semana. ${ }^{2}$

\footnotetext{
${ }^{2}$ Se Lama Gangchen teve grande influência na vida de Mônica, poderíamos dizer que a recíproca também é verdadeira. Com efeito, Mônica desempenharia um papel fundamental na vinda de Lama Gangchen ao Brasil e na fundação de seu primeiro centro por aqui, em meados dos anos 80 . Foi um astrólogo francês que a apresentou a Isabel Villares e seu marido Daniel Calmanowitz, que criariam condições materiais para a visita de Lama Gangchen. Mônica decidiu procurar o astrólogo justamente porque estava pensando em trazer Lama Gangchen para o Brasil, e queria um conselho, talvez a indicação de alguém que pud esse ajudá-la nesse "projeto". Como conta:

"Um belo dia ele [o astrólogo] me telefonou e disse: tem um casal aqui e eles têm um mapa muito interessante e eu tenho a impressão de que eles podem ajudar a trazer o lama. Olha que loucura, né? Eu fui à casa da Bel no dia do aniversário dela, ela estava com a Fê [sua filha] no braço. Acho que ela tinha um ano e meio. Eu tinha voltado de Goa... imagina! Eu estava uma figura: cabelo preto todo repicado,
} 
O espanhol José-Maria Arocena, com quem conversei em Albagnano, onde também passa boa parte de seu tempo, conta uma história semelhante de transformação de vida - na verdade, uma cura pessoal - a partir de seu encontro com Lama Gangchen:

Foi assim que conheci Lama Gangchen,de certa forma um contato energético, porque ele não dava ensinamentos, somente pastilhas, o mantra de Shakyamuni e os quatro pensamentos ilimitados. ${ }^{3} \mathrm{E}$, em grupo, a prática de

unha verde metálica, cheia de escorpiōes, anel, não sei mais o quê... me achando chiquérrima: "Meu amigo la ma tibetano". E ela estava fazendo campanha contra o leite radioativo de Chernobil em São Paulo. Ela me olhou, mas não me discriminou. Começamos a conversar, eu contei pra ela de minha viagem com Lama Gangchen. A gente começou a se freqüentar. Comecei no fim de semana, eu ia para Ilhabela, depois ela vinha em casa. Dois meses depois, o Rinpoche estava em São Paulo."

Em 1988, um ano após essa primeira visita ao Brasil, Isabel, com a ajuda de outros que viriam a ser importantes discípulos de Lama Gangchen, como Eli Inoue, fundaria o centro de dharma Shi De Choe Tsog. Por volta dessa mesma época, Lama Gangchen reconheceria o filho de Isabel e Daniel, Michel, como a reencarnação de seu mestre, plantando assim importantes sementes para a continuidade de seu trabalho no Brasil e também no mundo.

${ }^{3}$ Os pensamentos ilimitados representam quatro tipos de estados mentais virtuosos - o amor, a compaixão, a alegria altruísta e a equanimidade. Eles são ilimitados porque dizem respeito a todos os seres sencientes. Sempre que se reúne com seus discípulos, Lama Gangchen faz a seguinte prece em várias línguas:

"Possam todos os seres sencientes ter felicidade e sua causa.

Possam todos os seres sencientes ser livres do sofrimento e sua causa.

Possam todos os seres sencientes jamais se separar da felicidade que não conhece o sofrimento.

Possam todos os seres sencientes viver no estado de equilíbrio contínuo, livres dos extremos da atração por uns e da aversão por outros" (Gangchen, 200 1).

Recentemente, Lama Gangchen acrescentou aos quatro pensamentos ilimitados outros três pensamentos: saúde, regeneração ecológica e a paz:

"Possam todos os seres se recuperar das doenças causadas pela poluição física e mental, e gozar de saúde relativa e absoluta agora e sempre. 
Tara Branca. ${ }^{4}$ Os pujas ${ }^{5}$ consertam, dizia. E com o tempo pude compreender porque ele dizia isso. Não acreditava que era algo mágico. Com Lama Gangchen, subíamos no ônibus e ele começava o puja, sempre. Entrávamos no carro, ele começava um puja. Comecei a me conectar com uma energia que não entendia. Para mim, era algo novo, pois sempre o que me atraiu no budismo era o controle mental, domar a mente, controlar os fenômenos, aprender a controlar as emoções, mas esse aspecto mágico eu não havia vivido até conhecer Lama Gangchen.

José-Maria conheceu Lama Gangchen em 1989, na Espanha, quando se recuperava de problemas emocionais causados por uma relação amorosa mal resolvida. Ele conta que resolveu ajudar o lama, em suas consultas. "Não fazia nada de extraordinário: ficava do lado de fora e explicava às pessoas que entravam e saíam como tinham que tomar o remédio. Mas via que todos saíam com um sorriso radiante. Todos entravam com o peso da doença e saíam leves." José-Maria conta que, para trabalhar com Lama Gangchen, se levantava às seis da manhã e quando chegava em casa já eram onze da noite. "Foi assim durante uma semana, mas me sentia com uma energia impressionante. Mas o impressionante mesmo foi quando vi aquela mulher [sua ex-namorada] num daqueles dias: era como se houvesse desaparecido tudo, todo meu apego; eu havia mudado!" Ele se viu curado de seus problemas emocionais. A partir dessa experiência, José-Maria, apesar

Possam todos os seres relaxar num meio ambiente interno e externo puro e saudável, agora e sempre.

Pos sam todos os seres desfrutar da paz interna e paz no mun do agora e sempre" (Gangchen, 1999 , p. 15). Como ficará claro ao longo deste trabalho,essa adaptação de um ensinamento clássico está em direta relação com as atuação de Lama Gangchen no Ocidente. Saúde, Ecologia e Paz Mundial representam, na verdade, os pilares sobre os quais assenta suas atividades.

${ }^{4}$ Tara representa o princípio feminino da iluminação. Tara é a bodhisattva da atividade compassiva. Existem inúmeras manifestações de Tara, entre elas a Tara Branca, que normalmente é associada à longevidade.

${ }^{5}$ Puja (sânsc.) quer dizer literalmente "oferenda". Normalmente se refere a uma oferenda associada a um ritual ou a recitação de uma sadhana. 
de suas limitações físicas - cerca de dez anos antes, quando tinha apenas vinte e seis anos, um acidente automobilístico o deixara paralítico da cintura para baixo - decidiu acompanhar Lama Gangchen em suas viagens, ajudando-o.

Várias são as indicações sobre a inserção de Lama Gangchen no Ocidente que nos dá a história do encontro de José-Maria. Em primeiro lugar, a visão que tem o espanhol de seu contato com o mestre tibetano é de uma nova forma de cura. Já não estamos falando agora apenas de doenças físicas, mas também de um mal de fundo puramente emocional. Em um certo sentido, o tipo de cura que Lama Gangchen realiza se aproxima aqui da própria idéia de cura como metáfora para o caminho rumo à iluminação no budismo como um todo. Isso indica ainda um outro aspecto de como se estruturou o encontro de Lama Gangchen com seus discípulos. Como relata Gabriella Ferro, uma jovem (porém antiga) aluna italiana: "ele começou como um lama-curador, visitava os pacientes, fazia bênçãos, e curava. Através dessa cura do corpo, muitos iniciavam também uma cura espiritual. Muitos de seus discípulos foram um dia seus pacientes".

Em suas peregrinaçôes ao lado de Lama Gangchen - por vários meses, viajou pela Europa, e depois visitou países da Ásia, como a Indonésia e o Nepal - José-Maria nos aponta ainda para outra faceta muito particular do lama tibetano: as viagens tornaram-se uma forma de ensinamento em si (e também uma forma de cura). Aos poucos, como aconteceu no caso de JoséMaria, alguns discípulos foram se reunindo em torno de Lama Gangchen principalmente em seu centro de Milão - e com ele começaram a visitar importantes lugares de peregrinação, e também países onde o lama havia fundado centros de dharma. A primeira grande viagem aconteceu em 1987, quando Lama Gangchen voltou ao Tibetepela primeira vez, desde que fugira do país. A viagem foi improvisada (muitas vezes não se sabia onde iriam passar a noite), mas foram plantadas, na ocasião, algumas importantes sementes como, por exemplo, a reconstrução futura do Monastério Gangchen, que fora destruído durante a Revolução Cultural. Também se abriu a partir dessa primeira viagem a possibilidade do retorno anual ao Tibete para um grupo de discípulos que, ao longo dos anos, ficaria cada vez maior. 
Gabriella, que mora e viaja junto a Lama Gangchen desde o início da década de 90, quando tinha apenas vinte e um anos, acredita que existam dois aspectos no que diz respeito às viagens como uma forma de prática: "em primeiro lugar, trata-se de uma prática de acumulação de méritos, uma vez que sempre vamos a lugares de peregrinação, Borubodur,Tibete, Nepal. Ele viu que as pessoas estavam interessadas no budismo, então decidiu levar as pessoas diretamente a esses lugares”. Nesse sentido, Gabriella destaca ainda a possibilidade de se receberem bênçãos e, portanto, mesmo de ser curado, na visita de um lugar sagrado.

Muitas vezes eu pude observar a diferença de uma pessoa no início e no final de uma viagem. Me lembro uma vez o caso de um rapaz inglês que veio a Borubodur, e lhe haviam dado dois meses de vida, pois havia feito uma operação na cabeça, tinha um tumor. E ele ainda vive, e depois dessa viagem a Borubodur [1998], teve uma grande cura. Seguramente não foi apenas a viagem, houve uma série de combinaçôes, mesmo cármicas, e de predisposições mentais. Em todo caso, ir a lugares sagrados é algo que os budistas - e mesmo os cristãos - sempre fizeram.

Ou tro de seus discípulos, que vive a seu lado - antes em Milão e agora em Albagnano - desde meados dos anos 80, o artista plástico Leonardo Ceglie, ou Duccio como é mais conhecido, enxerga nas viagens de peregrinação o cerne mesmo da "man eira de ensinar" do lama. "Ao invés de explicar como se vive na Indonésia e que diferença existe entre um lugar e outro, ele te leva lá e daí nasce um tipo de sabedoria." E continua:

Você começa a pensar como se vive no mundo. Compreende que lá é diferente, porque faz mais calor, faz mais frio. Começa a raciocinar de uma outra maneira, uma mente maior. Sabe que se pode dormir na rua, ou ainda em um hotel de US\$ 400. Tudo somado, você compreende onde está a diferença, talvez nem exista uma diferença. Resumindo, você se torna um outro. Nesse caminho espiritual... por exemplo, quando existia o Buda histórico, ele andava a pé, pela floresta, com seus discípulos, de cidade em cidade. Cobriu uma área muito grande. Hoje Rinpoche vai de avião. É muito fácil. Chega a ser mais fácil de aprender. 
Assim, as viagens representariam, entre outras coisas, uma forma direta de entrar em contato com o "outro", e a partir daí relativizar sua própria identidade, um princípio básico dos ensinamentos budistas, que enfatizam justamente a ausência de existência inerente das coisas e, mais especificamente, o conceito de não-self, ou não-eu.

A respeito das viagens, valeria ainda destacar aqui mais um aspecto levantado por Gabriella. Segundo ela, Lama Gangchen é capaz de “revitalizar energeticamente" os lugares por onde passa: "por exemplo, a China, onde existem tantos lugares sagrados, mas que ficaram 'abandonados' por tanto tempo, quando ele vai a esses lugares, acaba por revitalizá-los". O significado das viagens, incluindo essa última particularidade, e o entendimento de Lama Gangchen sobre a noção de cura só ficariam mais claros para seus discípulos um pouco mais tarde, durante o que se poderia chamar a segunda fase de sua estadia no Ocidente.

\section{Corpo, Palavra e Mente}

Lama Gangchen costuma dizer que, durante os dez primeiros anos de sua estadia no Ocidente, deu a seus discípulos seu "corpo", nos dez anos seguintes sua "palavra", e finalmente que, em outros dez, ele daria sua "mente". A alusão aqui é feita ao corpo, palavra e mente do Buda, seus três aspectos iluminados, ou ainda aos três corpos de Buda: nirmanakaya, sambhogakaya e dharmakaya. Trata-se de uma representação simbólica fundamental, sobretudo ao budismo tântrico.No casode LamaGangchen,seus discípulosentendem essa "oferenda do corpo" como sendo justamente sua prática de curar milagrosamente doenças, especialmenteas físicas. Gradualmente, Lama Gangchen abandonaria essa prática mais direta para enfatizar outros aspectos da noção de cura. Na verdade, em muitos sentidos, seu dom seria "ampliado", ganhando desdobramentos novos e inusitados.

Depois de quase dez anos de poucas palavras, Lama Gangchen passaria a dar ensinamentos cada vez mais complexos a seus alunos. Seu primeiro livro, AutocuraI, foi publicadooriginalmente no Brasil, em 1991. Tratava-seda trans- 
criçãode um workshop que o lama tibetano realizou no Centro de Dharma Shi De ChoeTsog,em abril de 1990. No livro,a idéia de autocura, central a todos os seus ensinamentos, seria pela primeira vez expressa por escrito. Em linhas gerais, Lama Ganghen identificaria as causas de nossas doenças em fatores internos, apontando assim para uma possibilidade de cura através da autotransformação. A maneira como era apresentada essa noção de autocura não era, dizia, tradicional. Seria através de exemplos práticos, como o vício causado pelo cigarro, o álcool ou o café,que Lama Gangchen desenvolveria sua teoria sobre nossos "inimigos e amigos internos". Em uma linguagem simples e direta, ele explica, por exemplo, a nossa relação com o cigarro:

Em nossa mente, sempre temos o pensamento de que o cigarro é nosso amigo, de que ele nos ajuda. Isso se dá porque nossa mente está bastante próxima desse objeto. Pensamos: 'Ah! Um amigo deve ficar muito próximo e um inimigo deve ficar bem longe'. Por exemplo, ao comprarmos um maço de cigarros, logo o colocamos próximo de nosso corpo, muitas vezes dentro do bolso, perto do coração; e se fosse possível, faríamos um buraco para colocálo dentro dele (Gangchen, 2001, p. 47).

É preciso ressaltar, no entanto, que se Lama Gangchen partia de exemplos relacionados diretamente com o cotidiano dos ocidentais, o método de "cura interior" que era proposto tinha firmes raízes em ensinamentos mais tradicionais - um equilíbrio entre o "moderno" e o "tradicional" que, sem sombra de dúvida, o lama tibetano procurou desde sempre. Já nesse primeiro momento em que articulava em palavras seus ensinamentos, era clara a preocupação em apresentar os mét odos bud istas segundo parâmetros compreensíveis ao público "moderno" com que en trava agora em contato. Era preciso "ensinar à nossa mente" que o cigarro nos fazia mal, que era nosso verdadeiro inimigo. Era preciso combater esse "hábito mental negativo" e ouvir nosso corpo. "Quando tragamos sentimos mais energia, mas depois começamos a tossir. Isso significa que o nosso corpo está sofrendo. Ele reage ao mal que lhe fazemos com o som da tosse, como se estivesse dizendo: 'Isso me faz mal, isso me faz mal"' (Gangchen, 2001, p. 12). Os vários níveis a partir dos quais a noção de cura deve ser entendida dentro do budismo mos- 
travam-se aqui em sua real inextricabilidade. $\mathrm{Na}$ verdade, como veremos, podem-se "ler" os desdobramentos da atuação de Lama Gangchen no Ocidente no sentido de uma transparência crescente dessa inextricabilidade. Em todo caso, o que se depreende do trabalho de Lama Gangchen até aqui é que a cura não era algo que vinha de fora: "domar a mente", o mais fundamental entre os métodos budistas, poderia nos levar não apenas à nossa "cura definitiva”, ou seja, à iluminação, mas também à cura de doenças físicas (e mentais).

A publicação de outro livro, Autocura II, em 1993 - primeiramente no Brasil e posteriormente na Europa, em inglês e italiano - represen taria um marco decisivo na história da inserção de Lama Gangchen no Ocidente. No novo livro, a idéia de "autocura", que vinha sendo até en tão tratada em termos gerais, ganha novas e mais específicas acepçôes. Em Autocura II, era apresentada pela primeira vez a chamada "autocura tântrica ngel so", uma prática espiritual que combinava melodias ocidentais, mantras, mudras, visualização e concentração nos chakras internos, com o intuito de "nos ajudar a perceber e curar as nossas energias sutis do corpo e da mente e aprender a usá-las de maneira correta” (Gangchen, 1993, p. 14).

Tratava-se, antes de mais nada, de um inovador ritual tântrico. Seus fundamentos, é certo, estavam fortemente arraigados em conhecimentos tântricos tradicionais. Esses últimos, porém, encontravam-se de tal forma "destilados" no novo formato que o resultado final era diferente, ao menos em aparência, de tudo que se havia visto até então em termos de práticas budistas tibetanas. Não poderíamos jamais enfatizar suficientemente o que significou a criação dessa nova prática budista tibetana. Não que Lama Gangchen quisesse romper com seus gurus ou com a tradição a que pertencia, ${ }^{6}$ a Guelugpa, mas ao compor um ritual não ap enas novo - isso seria até

\footnotetext{
${ }^{6}$ É preciso que fique claro que Lama Gangchen associa diretamente a prática de autocura tântrica ao conjunto de ensinamentos pertencentes à sua linhagem. Lemos, por exemplo, em seu prefácio ao livro Autocura II: "Esse ensinamento secreto para a purificação dos chakras foi transmitido, através da linhagem ininterrupta de BuddhaVajradharaao meuguru-raiz, Ganden Kargiu Tchaguia Tchenpo". E um pouco mais adiante: "Compus este texto com a permissão do meu Guru e do meu Yidam [deidade tântrica]" (Gangchen, 1993, p. 30).
} 
relativamente usual - mas inovador em seu formato e concepção geral, e ainda para o benefício de ocidentais, ele caminhava com vigor para uma autonomi zação de sua atividade espiritual. A validade da "autocura tân trica" poderia até ser corroborada por outros representantes da Escola Guelugpa, mas tal prática certamente não seria (ao menos não imediatamente) introduzida nos meios tibetanos.

Se Lama Gangchen gradualmente declarava uma certa independência em relação ao tradicionalismo de sua escola original, ele paralelamente ampliava o escopo de sua atuação no Ocidente. Assim, talvez um dos aspectos mais importantes do livro Autocura II seja um certo sentido missionário a partir do qual passa a ser apresentada sua atividade espiritual, e que ele mesmo estende a outros lamas. Lama Gangchen apelidou esses lamas e ele próprio de "Lamas Marco Polo". Como diz: "Guiados pela compaixão, os Lamas Marco Polo - os lamas tibetanos - estão criando o budismo ocidental" (Gangchen, 1993, p. 11).

\section{SHAMBHALA}

Seria interessante notar que tal sentido missionário está expresso na própria estrutura da chamada "autocura tântrica”, uma vez que essa prática foi composta primariamente em referência a uma profecia que prevê que, em cerca de trezentos anos, acontecerá uma batalha entre os "guerreiros iluminados" de um reino mítico chamado Shambhala e "forças materialistas que serão então dominantes no planeta". De acordo com uma vasta litera tura relacionada ao sistema tântrico de Kalachakra, ${ }^{7}$ o reino de Shambhala existiria em nosso mundo, mas estaria escondido atrás de uma bar rei ra invisível. Em Shambhala, reis iluminados zelariam pelos ensinamentos budistas mais secretos, preservando-os para uma época em

\footnotetext{
${ }^{7} \mathrm{O}$ Tantra de Kalachakra é considerado um dos mais secretos e intricados sistemas do chamado budismo tibetano. Sua literatura fundamental inclui assuntostão variados quanto a astrologia, a geomancia, a geografia, a história, a psico-fisiologia humana e a escatologia.
} 
que "toda a verdade no mundo exterior estará perdida na guerra e na luta pelo poder e riquezas" (Bernbaum, 1980, p. 4). É nesse momento, segundo a profecia, que o futuro rei de Shambhala comandará seu exército de guerreiros iluminados contra as forças do mal. A vitória trará uma era dourada para a humanidade, e o mundo se transformará finalmente em um lugar de paz e abundância.

Lama Gangchen instiga, portanto, seus discípulos a prepararem-se para a "batalha final" que deverá envolver toda a humanidade, devendo todos "conecta[r] seus coraçóes com a energia de Shambhala" (Gangchen, 1993, p. 25). Não seria exagero dizer que Lama Gangchen vem organizando, em muitos sentidos,sua práticaespiritual e a atividadeem seus centrosde dharma com base na preparação de seus discípulos e adeptos para o confronto que, como explica em seus livros, deve ser entendido em diversos níveis. Lama Gangchen enfatiza principalmente o sentido alegó rico da guerra de Shambhala, descrevendo-a como uma batalha entre forças negativas e positivas nos chamados "níveis externo, interno e secreto":

Assim, a guerra externa de Shambhala e os senhores da guerra são uma alegoria do verdadeiro combate espiritual interno e secreto de Shambhala. Ela se refere ao fortalecimento do nosso poder interno e secreto de autocura, ao desenvolvimento do nosso Guru interno (Rigden) e dos guerreiros de sabedoria, que acabam com os nossos inimigos - as 84.000 ignorâncias, a nossa mente negativa, os venen os mentais, o ego e outros estados de consciência perturbados e distorcidos (Gangchen, 1993, p. 27).

Os “inimigos internos” de que falava Lama Gangchen em Autocura I ganham aqui um tratamento mais "técnico", em concordância com a terminologia budista. O budismo identifica 84.000 tipos de obscurecimentos mentais, provenientes de cinco ilusões primárias: a ignorância,o apego, a raiva, o orgulho e a inveja LamaGangchen identifica essesúltimos como os "nossospiores inimigos" e nos alerta que deles provêm todos os nossos sofrimentos, o que inclui doenças, guerras, desastres, fome etc. Assim, aos poucos, o lama tibetano vai construindoa idéiade que está em nossas mãos mudarnão apenas nossas vidas, mas também as condiçóes externas que nos rodeiam. Nesse sentido, Lama 
Gangchen apresenta a guerra de Shambhala como uma possibilidade de cura derradeira, não apenas para "nossos corpos e mentes", mas também para a sociedade, o meio ambiente, o planeta e até mesmo o cosmos.

Subjacente a essa visão de Lama Gangchen está a idéia de interligação entre macrocosmos e microcosmos, uma noção que seria refinada em futuras publicações e ganharia novos significados através de sua atuação no Ocidente. O lama tibetano baseia-se no tantra de Kalachakra para desenvolver a noção de que o universo e o nosso corpo estão diretamente relacionados. Em seu livro Fazendo as Pazes com o Meio Ambiente, publicado pela primeira vez em 1995, na Itália, que Lama Gangchen elabora ainda mais detalhadamente tal idéia. De maneira muito sucinta, a passagem abaixo descreve em linhas gerais no que consistia a nova prática que era então introduzida por Lama Gangchen, a "au tocura do meio-ambiente":

Segundo o Tantra de Kalachakra, temos em nosso corpo e mente exatamente os mesmos elementos e energias que encontramos no meio ambiente externo. Portanto, se trabalhamos os elementos de nosso meio ambiente interno no nível energético, podemos influenciar positivamente os elementos e energias do meio ambiente externo. Temos em nosso corpo cinco consciências e cinco elementos: espaço, vento, fogo, água e terra. Esses elementos e consciências também existem no mundo externo. Nesse livro explico como lidar com os fluxos de energia sutil, ou "ventos" dos elementos, usando chaves mântricas, mudras, visualizações e concentração. Dessa forma, podemos desbloquear e purificar as energias dos cinco elementos: EH, espaço; LAM, terra; YAM, vento; BAM, água; RAM, fogo. Purificar os fluxos de energia sutil em nosso meio ambiente interno (nosso corpo e mente) e no meio ambiente externo (o universo) causa a recuperação da saúde física, purifica as cinco consciências, cura o meio ambiente e o cosmos e muitas manifestaçôes sociais negativas ocasionadas por desequilíbrio dos elementos (Gangchen, 1999, p. 41).

Assim, a mesma idéia que estava expressa já na prática de "autocura tântrica", a idéia de in tegração entre microcosmo e macrocosmo, era aqui aplicada diretamente ao meio ambiente externo, visando sua "cura", sua purificação, através de um ritual tântrico. Durante o retiro que fizemos, na 
Amazônia, no final de 2000 e começo de 2001, Lama Gangchen nos deu um exemplo concreto desta idéia, ao realizar, nas areias do Tapajós, uma prática que envolvia a recriação simbólicada célebre estupa de Borobudur. Enquanto andávamos pelas areias, reproduzíamos mentalmente as paredes do monumento javanês.Em um movimento circular, íamos visualizando a regeneraçáo da floresta a partir da multiplicação de flores de lótus de várias cores em todas as direçōes. Em alguns momentos, Lama Gangchen proferia: "Amazônia: centro do mundo, pulmão do mundo". Caminhamos, nessa "realidade virtual", até o centro do mandala - o "topo" da estupa-, onde Lama Gangchen se sentou e, juntamente com Lama Caroline, nos deu ensinamentos.

Lama Caroline comentou que essa prática era exatamente como a autocura, "só que na autocura vamos de cima para baixo e, no caso desse mandala, vamos pelos lados, em todas as direçōes". "Borobudur, na época em que foi construído," ela dizia, "ficava no centro da ilha de Java e representava o centro do mundo. Agora também podemos imaginar esse mandala de Borobudur no centro do mundo, com os continentes que a gente conhece em volta”. Lama Gangchen, por sua vez, explicou que o que fazíamos ali era uma forma de "educação ambiental": "estamos aqui com o próprio lama, transformando elementos impuros em puros. Trata-se, portanto, de um tipo de educação ambiental prática e não teórica."

Seria interessante notar aqui que não apenas era a noção de cura agora estendida ao universo como um todo, como também, e de modo ainda mais importante, essa compreensão ampliada passava a ser a única possível. Com efeito, nossa saúde, diria Lama Gangchen, está diretamente ligada ao meio ambiente externo; para nos curarmos, precisamos, portanto, curar o universo. Em uma palestra com o título de A Importância da Amazônia na Cura do Meio Ambiente Interno e Externo, que deu em São Paulo, em janeiro de 2001, Lama Gangchen expressou claramente essa idéia. Segundo o lama, não deveríamos pensar que a questão ambiental fosse tão somente um "problema do mundo", externo a nós mesmos.

Na realidade, o meio ambiente está totalmente ligado à nossa saúde, já que hoje em dia a mediàna não pode nos ajudar tanto no que diz respeito à nossa saúde. 
Os médicos estão fazendo o melhor que eles podem, mas existem tantas doenças novas surgindo que eles não sabem como ajudar. Eles aprendem na Faculdade que tal doença se trata com tal remédio, mas o que acontece hoje é uma grande confusão. A mediaina não está funcionando, não traz resultados. $\mathrm{O}$ médico não consegue formar um quadro [a partir dos exame] que possa dizer como ele pode tratar aquela doença. O queeles nãoentendem é a relaçãoentre causas e condiçōes, é muito difíal para eles. Então, por que ficamos doentes? Porque nosso meio ambiente está poluído, nosso dia-a-dia está de ponta-cabeça, tudo está diferente. Nosso corpo, nossa mente, nossas emoçoes, tudo está diferente.

Ainda de acordo com Lama Gangchen, a Terra inteira estaria intoxicada, cheia de venenos, e isso acabaria nos afetando, tanto coletivamente quanto pessoalmente. Seria preciso, como diz o lama, conscientizar-nos de que nosso alimento vem da Terra, e de que esse alimento está cada vez mais intoxicado porque poluímos o solo onde era plantado. "Esse alimento", ele afirma, "mata um pouco nossa fome, mas na verdade está nos envenenando". Em sua opinião, nossas doenças são, na maior parte dos casos, "efeitos colaterais" desses tóxicos que estamos ingerindo. Seria interessante atentar para o fato de que, além de propor uma prática espiritual para "curar o meio ambiente", Lama Gangchen também sugere aqui (e, como veremos, em outras instâncias) um esforço no sentido de uma conscientização coletiva sobre os problemas do mundo, um projeto de educação, ou de "educação não-formal", como ele mesmo chamaria. Tal projeto se tornaria, de certo modo, o pano de fundo para todas as atividades de Lama Gangchen, e iria muito além da questão ambiental ou da saúde pessoal para englobar a vida como um todo.

Como explica José-Maria, que trabalha junto ao lama em projetos ligados à educaçãonão-formal em vários lugaresdo mundo, mas especialmente na Europa:

A educação não-formal tem que começar antes mesmo do nascimento, quando a mulher está grávida. A relação da mulher com o feto, do marido com a mulher e a criança que está para nascer. É precisoestabelecer uma relaçãomuito especial com esse ser que está nascendo. Caso contrário, o feto nasce assustado e assume já todo esse medo. Os primeiros anos da educação de uma criança 
também são importantes. Como se relacionar com uma criança, sem violência, sem agressividade. Quando se torna adolescente, há um tipo de educação para controlar os tipos de emoções, a paixão que tem, por exemplo, um garoto de quinze anos. Como trabalhar e controlar essas emoçōes? Quando alguém fica doente, a educação para a doença, como viver essa doença? Quando morre um ente querido, como trataro tema da morte? Desenvolver isso para que se chegue a um manual de como viver melhor, essa é a educação não-formal.

$\mathrm{Na}$ verdade, poderíamos detectar esse mesmo esforço na direção de instigar uma "educação não-formal" já no livro Autocura I, quando o lama adverte as pessoas sobre os problemas (e a "falsa amizade") do cigarro, do café e do álcool. Poderíamos deduzir a partir daí que é de sua observação do modo de vida ocidental, e de sua tentativa em trazer para o domínio prático os ensinamentos budistas, que nasce a noção de que existe no mundo hoje uma necessidade de um tipo de educação que não se pode adquirir em uma Faculdade ou em qualquer outro estabelecimento de ensino convencional. Uma das preocupações de Lama Gangchen é, portanto, a criação de espaços onde a "informação", como ele mesmo coloca, possa ser transmitida. A prática espiritual representaria, certamente, uma maneira de se chegar a esse tipo de aprendizado. Lama Gangchen, porém, não limitaria seu escopo de ação a grupos de discípulos, mas o ampliaria para instâncias não necessariamente relacionadas com a esfera religiosa.

\section{Institucionalizar é Preciso...}

Com efeito, desde cedo, a atuação de Lama Gangchen no Ocidente mostrou-se bastante diversificada, abarcando mais de uma área. Em 1992, na ocasião da criação da Lama Gangchen World Peace Foundation (LGWPF), ${ }^{8}$ organização não-governamental que daria a todas as suas ativi-

\footnotetext{
${ }^{8}$ Apesar de Lama Gangchen residir na Itália, por razões burocráticas, o LGWPF foi criado na Espanha. Aparentemente era mais fácil criar uma organização desse tipo dentro da legislação espanhola. Em todo caso, o LGWPF sempre funcionou, na prática, na Itália.
} 
dades um denominador comum, o lama tibetano atuava, é certo, no campo da espiritualidade, mas também já realizava trabalhos de cunho humanitário havia alguns anos. Como comenta a inglesa Sharon Dawson a respeito da Help in Action, o braço de ajuda humanitária da LGWPF que fora criado juntamente com a Fundação:

Eu gosto de pensar que o Help in Action começou há muito tempo atrás, quando Lama Gangchen ainda morava na Índia. Os tibetanos mais velhos dizem que Lama Gangchen é um lama puro, não apenas porque ele é puro [no sentido espiritual], mas porque ele é o único lama que ia à casa das pessoas com presentes, como um saco de arroz - em geral quando um lama te visita, você tem que oferecer algo a ele.

Em seu minúsculo apartamento - que também serve de sede para a Help in Action e ainda para a Peace Publications, editora do grupo de Lama Gangchen - Sharon, que trabalha como voluntária à frente da Help in Action, diz que o lama tibetano costumava fazer empréstimos para ajudar as pessoas, e depois outros mais para pagar os que já havia feito. O Help in Action começou, nesse espírito, com apenas duas famílias; hoje, diz Sharon, são mais de duas mil.

O Help in Action ajuda famílias de tibetanos, indianos e nepaleses, em seus países de origem, abarcando as áreas de saúde, educação e também infra-estrutura. A organização conta com doações e com o trabalho voluntário que, em grande parte, é feito pelos alunos de Lama Gangchen. Em 1999, por exemplo, Lama Gangchen viajou com cinqüenta ocidentais que trabalharam na reconstrução de seu monastério no pequeno vilarejo que leva seu nome. Foram arrecadados cerca de US\$300.000 para o projeto do vilarejo de Gangchen - que envolvia também a criação de serviços de educação e saúde em toda a área. Pormeio da LGWPF, Lama Gangchen também levou para a Europa monges tibetanos que, fazendo turnês de construção de mandalas de areia, levantavam fundos para seus respectivos monastérios. Em Katmandu, além de ajudar diretamente algumas famílias através do sistema de "adoção à distância", o Help in Action construiu uma clínica, o 
Healing Center, onde, pode-se dizer, Lama Gangchen trilhou o caminho inverso daquele que havia tomado no Ocidente. Nas palavras da suíça Isthar Adler, que representa a LGWPF em nome de Lama Gangchen na ONU:

Nós promovemos um tipo de intercâmbio, oferecendo a médicos ocidentais a oportunidade de passar algum tempo na Ásia, para levar saúde à população local e, ao mesmo tempo, aprender com ela que tipo de problemas elas têm. Naturalmente, se esses médicos decidiram ir para o Nepal, eles se sentem atraídos por essa cultura - de outro modo, eles iriam para a África, por exemplo - e procurarão saber mais sobre a cultura local, sobre a medicina local. Assim, nós criamos um espaço onde é possível também aprender sobre a medicina natural do Himalaia.

O envolvimento de seus discípulos (e mesmo de simpatizantes) nesse tipo de trabalho voluntário e também em contribuiçôes financeiras pode e, em muitos sentidos, deve ser entendido no contexto da "educação nãoformal" preconizada por Lama Gangchen. Ocidentais eram, por meio da ajuda humanitária, colocados em contato com realidades muito diferentes das suas, passando a ter uma visão mais global do mundo e de seus problemas - um tipo de aprendizado que, como vimos, também era pretendido com as viagens de peregrinação. Na prática espiritual, com seu trabalho de ajuda humanitária, e em suas viagens de "turismo espiritual", como gosta de chamá-las, o lama tibetano ia costurando conexôes entre diversas partes, aspectos e pessoas do mundo, e ainda entre as várias facetas de sua diversificada atuação. A noção de interdependência entre todos os fenômenos, central ao budismo, é, em muitos sentidos, a idéia que vai estar por trás do conjunto das suas atividades e da sua concepção de educação nãoformal. Da mesma forma, poderíamos localizar na idéia da 'paz mundial' a confluência (quase natural) de suas aspiraçôes, o que fará deste um tema central e, de certa maneira, o significado derradeiro do tipo de busca espiritual que propõe. Como costuma dizer, "a paz interior é a melhor base para a paz mundial". Tais noçôes norteiam a descrição dos objetivos da LGWPF: "Os principais objetivos da fundação são dar apoio ao desenvolvimento da paz mundial através da criação de condições para um verdadeiro sistema 
educacional voltado para a paz interior em todos os níveis, e por meio da promoção de intercâmbios concretos entre Oriente e Ocidente nos campos cultural, espiritual e material".

A afiliação da LGWPF à Organização das Nações Unidas em 1995 representaria, em muitos sentidos, a solenização de seus esforços para estabelecer as bases de sua prática espiritual e, na verdade, de suas atividades em geral, em um plano no qual o local e o global, o microcosmoe o macrocosmo, pudessem estar sempre em diálogo. Como conta Isthar Adler, "Lama Gangchen sempre disse que ele não estava aqui para buscar uma pequena paz, mas que ele queria contribuir para a paz mundial. 'Não funcionará', ele costuma dizer, 'a não ser que exista paz em toda a parte'. Assim, a ONU era para ele o lugar perfeito”. A oportu nidade de afiliação surgiu na ocasião da celebração do jubileu da ONU. Convidado a participar das festividades, Lama Gangchen aproveitou o ensejo para propor a criação de um fórum espiritual permanente que pudesse opinar em assuntos relacionados com a paz mundial. A idéia ainda era embrionária, mas criou um grande burburinho. Segundo Isthar, Lama Gangchen recebeu "muitos e importantes feedbacks; a partir daí, nós decidimos pedir a afiliação”.

O processo para a criação do fórum na ONU ainda está em andamento. Em uma proposta concluídaem 1999, Lama Gangchen definia o "Fórum Espiritual das Nações Unidas pela Paz Mundial” como

um espaço permanente para os líderes e representantes de todas as pequenas e grandes religiōes e movimentos espirituais poderem dialogar, tornando-se assim uma ponte para o Fórum Político. O conceito de Fórum Espiritual não imporá a criação de uma nova doutrina multi-religiosa-filosófica. Não pretende extinguir a diversidade cultural religiosa, mas será baseado no conteúdo de cada tradição e identidade, descobrindo, através do diálogo, os valores, conceitos e objetivos comuns, para agirem de pleno acordo em busca da paz interna e mundial, mantendo o direito de cada grupo cultivar, praticar e ensinar a sua própria doutrina.

Dentro desse espírito, o Fórum Espiritual deverá: oferecer espaço e canais que propiciem um melhor conhecimento e compreensão das crenças, códigos 
éticos, organização e práticas de cada um, condições básicas para o respeito mútuo; trocar idéias e desenvolver planos conjuntos a partir de uma perspectiva espiritual, para os principais problemas e desafios da humanidade, tais como a erradicação da pobreza, o crescimento populacional, a proteção do meio ambiente; identificar áreas para a ação comum, na promoção da paz (Gangchen, 1998, p. 24).

A afiliação à ONU representou o mais importante aspecto do gradual processo de institucionalização das atividades de Lama Gangchen. O lama tibetano ingressava agora em um terreno ao qual nem mesmo o Dalai Lama, devido a pressões chinesas, tinha acesso.

\section{CONSIDERAÇÕES FINAIS: ENTRE O LOCAL E O GLOBAL}

No dia seguinte à tempestade, nos reunimos embaixo de uma bela árvore e Lama Gangchen falou um pouco sobre os acontecimentos da noite anterior. Falou da tempestade principalmente em termos dos elementos e de como eles se manifestaram ali: o elemento ar ou vento, como ventania; o elemento água, como rio revolto; o elemento fogo, como raios, e assim por diante. Afirmou que era importante que conhecêssemos os elementos externos, que aprendêssemos com eles e, a partir daí, entendêssemos a relação inerente entre esses e os nossos próprios elementos. Esse, em sua opinião seria um passo essencial para que o grupo superasse o medo que sentira durante a tempestade. Lama Gangchen também disse que era importante que todos expressassem como viveram o acontecido da noite anterior. Assim, em uma verdadeira terapia de grupo, todos falaram de sua experiência com a tempestade: alguns se acusaram mutuamente, outros apenas expressaram o medo que sentiram, outros fizeram referências a mantras e rezas que teriam feito durante os piores momentos. Depois dessa verdadeira catarse coletiva, Lama Gangchen transmitiu a seus alunos uma prática de Tara que servia justamente para lidar com o medo. $\mathrm{Na}$ introdução à prática, lida em voz alta por Daniel Calmonowitz - o pai de 
Lama Michel -, o medo sentido por quase todos, no momento da tempestade, ganharia novas dimensões:

O nosso mundo tem sido permeado pelo medo. As pessoas têm vivenciado o sofrimento e o medo. Tudo aquilo que vemos ou tocamos pode causar danos ou sofrimento. Se nos relacionarmos de forma inábil, até mesmo o mais milagroso ocidental pode se tornar venenoso. Se observarmos bem, todos os fenômenos nesse mundo dualista são mutáveis. No nosso mundo samsárico, fenômenos mudam. Mesmo a experiência de prazer é como o mel numa lâmina de barbear. Um dia nosso melhor amigo pode se tornar nosso pior inimigo. Nossos cabelos ficarão cinzas, nossas roupas fora de moda. Todos os objetos de nosso mundo são transientes. Nós também temos medo das coisas que causam dor e sofrimento. A vida é um pesadelo. Fama e status social são passageiros. Temos medo da solidão, do tédio. Existe medo nas relações entre pais e filhos, medo do meio ambiente.[...]

Políticos têm medo de perder o poder. Pobres têm medos "financeiros" e "sociais". Muitos de nós podem achar que somos fortes. Se olharmos com cuidado nossas ações diárias mais básicas, vamos encontrar algum tipo de medo conectado com elas. Ao invés de ficarmos sobrepujados pelos nossos medos, precisamos de um meio natural para nos tornarmos destemidos. $\mathrm{Na}$ tradição tântrica tibetana, existe um método de nos familiarizarmos com nossos próprios medos. Tara é libertadora, é a consorte de Buda Amogasidhi, terapeuta absoluto do medo. Sua prática pode nos ajudar a nos libertarmos de nossos medos.

Talvez o aspecto mais fascinante a respeito da tempestade anunciada $\mathrm{e}$ da maneira como a "crise" foi tratada, na seqüência, por Lama Gangchen seja a conjugação entre os vários níveis de entendimento tanto da idéia de medo, quanto da própria idéia de cura.

O medo sentido duran te a tem pestade - en quan to não muito longe de nós, Lama Gangchen curava Manuel - tornou-se, para fins de "terapia coletiva", uma metáfora para os medos cotidianos. Além disso, esse medo foi descrito pelo lama tibetano como uma desarmonia entre os nossos "elementos internos" e os "elementos externos" materializados na tempestade 
como a ventania (elemento ar ou vento), o rio revolto (elemento água), e assim por diante. É clara aqui a referência à prática de autocura do meio ambiente como um caminho possível para a cura desse medo. Ainda nesse sentido, pode-se dizer também que a cura milagrosa de Manuel, ao ser relatada por Eugênio no dia seguin te, durante a sessão de "terapia coletiva" instigada pelo lama tibetano, ganhou uma nova conotação, que vem a reforçar o papel de curador de Lama Gangchen, em suas diversas implicações.

Poderíamos dizer que a cura realizada por Lama Gangchen, em plena Floresta Amazônica, acaba por se desdobrar em outras curas individuais, afetando, ainda que indiretamente, o conjunto de seus discípulos. Porém, levando um pouco adiante esse raciocínio, seria ainda preciso entender como a sincronia de diversos fatores - uma cura milagrosa, o medo e a catarse coletiva, a prática de autocura do meio ambiente como tema central da viagem e assim por diante - contribui para conferir novas e inusitad as implicações ao poder de curar do lama tibetano. De fato, ao ser analisado, através filtros que abarcam desde os diversos formatos de sua prática espiritual, até sua atuação junto à $\mathrm{ONU}$, um evento relativamente privado, como a cura milagrosa realizada por Lama Gangchen na Amazônia, acaba por ganhar dimensões mundiais (e mesmo universais).

\section{REFERÊNCIAS}

BERNBAUM, Edwin. The Way to Shambhala. Los Angeles: Jeremy P. Tarcher, 1980.

BIRNBAUM, Raoul. The HealingBuddha. Boston:Shambhala Publications, 1989.

CLIFFORD, Terry. Tibetan Buddhist Medicine and Psychiatry. York Beach (Maine): Samuel Weiser, Inc., 1984.

GANGCHEN,Lama. Autocura I: Proposta de um Mestre Tibetano. São Paulo: Editora Gaia, 2001. 
Fazendo as Pazes com o Meio Ambiente. São Paulo: Centro de Dharma da Paz Shi De Choe Tsog, 1999.

- Ngelso-Autocura III: Vol.1 - O guia para o Supermercado dos Bons Pensamentos. São Paulo: L.G. Saravasti, 1998.

Autocura II: Autocura Tântrica do Corpo e da Mente. Método de Paz Interior para Conectar este Mundo a Shambala. São Paulo: Sherab, 1993. 